\title{
MOBILIZING FOR NEW PARTNERSHIPS
}

\author{
Jack O. Burns \\ Vice Provost for Research \\ University of Missouri - Columbia
}

How do we, as mid-sized Great Plains universities, compete with the emerging "mega-universities" that are developing primarily on the two coasts of the United States? Institutions such as Johns Hopkins annually collect huge sums of money from the Department of Defense and NASA through their Applied Physics Laboratory. Similarly, the University of Washington is becoming a mega-academic-center for biotechnology. How do we challenge these universities for research funding? I propose a relatively simple approach for us to consider together-a strategy which can be described as collaboration and focus.

Let us first consider the power and potential of collaboration in strategic areas. This principle can be illustrated through the example of the Donald Danforth Plant Science Center (PSC) that was recently announced during ceremonies on July 31, 1998, in St. Louis. Four institutions in Missouri (the Missouri Botanical Garden, the Monsanto Company, the University of Missouri - Columbia, and Washington University) formed a unique partnership to address the age-old problem of "feeding the world" through basic research in plant science. Each partner has significant existing strengths and traditions in particular aspects of plant genetics, biology, and agriculture. Together, the partnership builds a collaboration that is unparalleled in both scientific expertise and alignment. We are unaware of another example of such a partnership that brings together a private university, a public land-grant university, a not-for-profit laboratory, and a for-profit corporation. An initial endowment for the PSC of nearly $\$ 150$ million was assembled from primarily private foundations, including the Danforth Foundation and the Monsanto Fund, along with $\$ 25$ million in tax credits from the state of Missouri.

The mission of the Plant Science Center is to:

- Contribute to human nutrition, health, and global sustainability by using innovative science to increase our understanding of plants, and applying that knowledge to improve productivity in agriculture;

- Promote practical application of new knowledge by facilitating rapid development and commercialization of biotechnologies;

- Contribute to education and training of students, postdoctoral fellows, scientists, and technicians from around the world. 
The Center, located in St. Louis, will have a full-time staff of 100 with 15 individual principle investigator-led multidisciplinary teams. A 150,000 square-foot building will soon begin construction. We at the University of Missouri (MU) will interact with the PSC staff and facilities, in part, via a novel virtual colaboratory. With the recently installed vBNS computer network connection between Columbia and St. Louis (funded by National Science Foundation grants to MU and Washington University), we will have the bandwidth for videoconferencing between researchers' computer workstations and the capability for remote operations of laboratory equipment (e.g., electron microscopes) over the internet. The PSC and its unique partnership will help to forge an emerging biotechnology corridor between Columbia and St. Louis.

Although it is too early to judge the level of success of the PSC, it has already had measurable benefits to the partnership. This collaboration has opened unprecedented lines of communication between our institutions. For the first time, MU and Washington University are exploring new avenues for interaction and cost-sharing (e.g., vBNS) in areas aside from plant science including computer engineering, neurobiology, and social work. It has also led to significant new funding by Monsanto for emerging biotechnologies across the full spectrum of the Life Sciences which are under development in the laboratories of MU faculty. Our faculty at MU are more actively pursuing commercialization of technologies developed in the laboratory in partnership with Monsanto and other corporations, and via independent start-up companies.

I believe that similar possibilities exist for collaboration between the three universities at this workshop-Kansas, Nebraska, and Missouri. Possible areas for collaboration include computer networking, plant and animal science, food production, chemistry, and telecommunications. Over the next year, we have agreed to work together to assess the core research competencies in our institutions, search for common research themes, and assist faculty in communicating between universities.

Focus is an equally important strategy in building successful research enterprises at universities such as ours. We have neither the fiscal nor human resources to be all things to all people in research. We must focus our resources to form core strengths in research areas that uniquely match our location, our history, and build on resident expertise. In the case of Missouri, we have identified Life Sciences as one of several existing areas of strength upon which we hope to build world-class research teams. The MU campus has a strong tradition of interdisciplinary research in the Life Sciences across five colleges including Agriculture, Arts \& Sciences, Human Environmental Sciences, Medicine, and Veterinary Medicine. Our strategy for enhancement includes:

- A commitment of $\$ 13$ million as a permanent budget increment for Life Sciences research from the state legislature over the next four years. The General Assembly in Missouri has already approved the first year's funding which will permit new faculty hires, laboratory remodeling, and student/postdoctoral fellowships. At the end of four years, we hope to have hired 40 new tenure-stream faculty in the Life Sciences. 
- An investment in a $\$ 49$ million Center for Life Sciences Research. This building will house up to 300 faculty, postdoctoral fellows, and students. It will provide state-ofthe-art laboratory space and facilities for research in strategically-determined areas within the Life Sciences.

- A National Center for Crop Genomics sponsored by funds from the state legislature and a major five-year grant from the National Science Foundation.

- The Danforth Plant Science Center endowed with funds from private foundations and Missouri tax credits.

- The MU-Monsanto grants program, a university-industry partnership, which is providing $\$ 2.5$ million in grants across the Life Sciences to support research in faculty laboratories.

I believe that focus and collaboration will allow us to successfully compete in selected areas of research with the larger research universities. Through selective teaming of faculty between our universities and with industry, we have the potential to excel and to innovate.

Research in the university environment has taken on an enhanced significance to the nation as industry has reduced its investment in basic research. Today's economy is driven by technologies whose geneses often lie in university laboratories. This trend will only accelerate in the future. Thus, university research takes on a new, unprecedented importance for the economies of our states and our region. University research is quickly becoming an economic development tool of major importance. As such, this will cause the basic mission of our universities to evolve in significant new ways. Research and teaching will become even more closely aligned as we bring more students into our laboratories for "real-world" experience with sophisticated laboratory equipment funded by state, federal, and industry sources. We must become more adept at articulating the new role of research within our universities to our state legislators. Our recent experience in Missouri suggests that legislators can embrace a major strategic enhancement in university research and they are willing to fund it for the benefit of its citizens. However, collaboration and focus must be in place if we are to successfully sell these plans to the legislators and taxpayers within our states. 